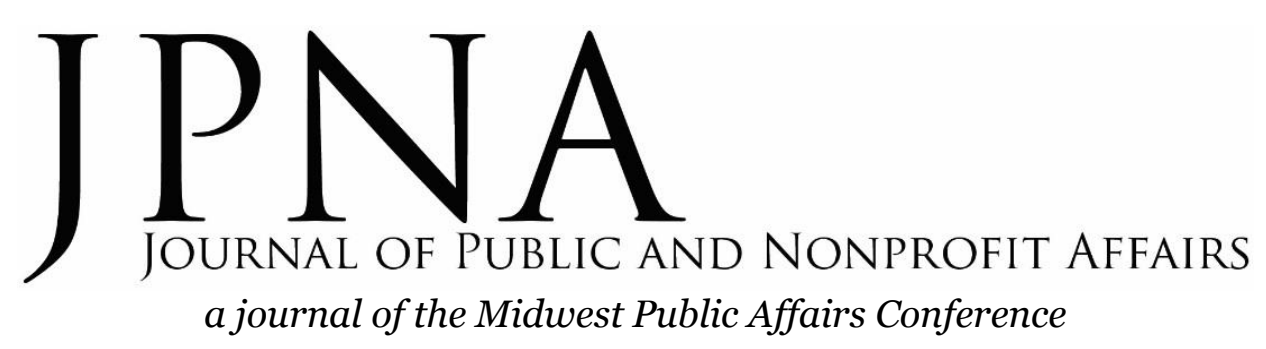

\title{
Spring 2017
}

\section{Volume 3, Number 1}

\section{Research Articles}

A Comparative Analysis of Two Streams of Implementation Research Stephen Roll, Stephanie Moulton, and Jodi Sandfort . . . . . . . . . . . . . 3

Exploring the Relationship Between Public Service Motivation and Formal and Informal Volunteering Richard M. Clerkin and Eric Fotheringham ..................... 23

Merging Ahead, Increase Speed: A Pilot of Funder-Driven Nonprofit Restructuring Robert L. Fischer, Diwakar Vadapalli, and Claudia Coulton. . . . . . . . . . . 40

Intelligence and Information Gathering Through Deliberative Crowdsourcing Benjamin Y. Clark, Joseph Logan, and Nicholas Zingale . . . . . . . . . . . . . . 55

\section{Current Issues in Practice}

City of Little Rock Neighborhood Alert Centers: An Assessment Report Hunter Bacot, Christopher Diaz, Bruce Moore, and Bryan Dayo . . . . . . . . . . . 79

\section{Book Reviews}

Diversity and Philanthropy: Expanding the Circle of Giving by Lilya Wagner Kathryn Yandell. ....................................... 100

Bringing Back the Bureaucrats by John J. DiIulio, Jr. by Ben Brunjes

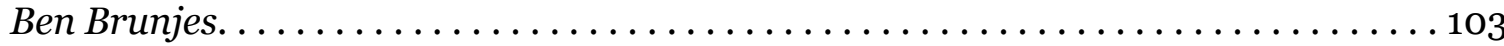


